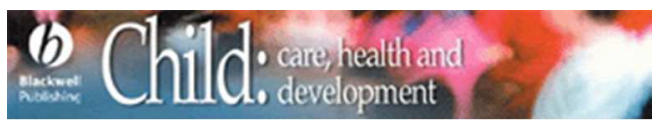

\title{
Does biological maturity actually confound gender-related differences in physical activity in preadolescence?
}

\begin{tabular}{|r|l|}
\hline Journal: & Child: Care, Health \& Development \\
\hline Manuscript ID: & $\mathrm{CCH}-2011-0137 . \mathrm{R} 2$ \\
\hline Manuscript Type: & Research Article \\
\hline Keywords: & $\begin{array}{l}\text { Accelerometry, Maturation, Movement behavior, Prepubescent, Sexual } \\
\text { dimorphism }\end{array}$ \\
\hline
\end{tabular}


Does biological maturity actually confound gender-related differences in physical activity in preadolescence?

Running head: Activity behavior and maturity status

\section{Authors}

Institution

\section{Corresponding author}

Child: Care, Health and Development 


\begin{abstract}
Aim: To examine a) if maturity-related gender differences in moderate-to-vigorous physical activity (MVPA) depend on how maturity status is defined and measured; and $b$ ) the influence of maturity level on compliance with PA recommendations.

Methods: The study involved 253 children (139 boys) aged $9.9 \pm 0.9$ years, with mean stature and weight of $1.39 \pm 0.08 \mathrm{~m}$ and $35.8 \pm 8.8 \mathrm{~kg}$, respectively. Their PA was evaluated using an ActiGraph accelerometer (Model 7164). Maturity was assessed using the estimated age at peak height velocity (APHV) and a standardized APHV by gender (i.e., centered APHV).

Results: Boys engaged in significantly more MVPA than girls $(\mathrm{P}<0.0001)$. There was a significant correlation between the centered APHV and MVPA in boys $(r=0.20 ; P=0.016)$, but not in girls $(r=0.13$; $\mathrm{P}=0.155)$. An ANCOVA controlling for the estimated APHV showed no significant interactions between gender and APHV, and the main effect of gender on MVPA was negated. Conversely, there was a significant main effect of APHV on MVPA $\left(F_{(1,249)}=6.12 ; P=0.014 ; \eta_{p}{ }^{2}=0.024\right)$. Only $9.1 \%$ of children met the PA recommendations, including $14.4 \%$ of boys and $2.6 \%$ of girls $(\mathrm{P}<0.01)$. This observation also applies in both pre-APHV ( $12.7 \%$ of boys vs. $2.4 \%$ of girls, $\mathrm{P}<0.001)$ and post-APHV children $(23.8 \%$ of boys vs. $3.4 \%$ of girls, $\mathrm{P}<0.0001$ ). No differences in PA guidelines were observed between pre-APHV and post-APHV children.
\end{abstract}

Conclusions: Among prepubescent children, the influence of biological maturity on gender-differences in PA may be a function of how maturity status is determined. The most physically active prepubescent children were those who were on-time according to APHV.

Key words: Accelerometry, Maturation, Movement behavior, Prepubescent, Sexual dimorphism 


\section{Introduction}

Physical activity (PA) plays a crucial role in the health of children and adolescents because risk factors for hypokinetic diseases (e.g., hypertension, diabetes) that occur in adulthood appear during early years of life, and may track over time (Chen \& Wang 2008; Morrison et al. 2008). This portends a growing health burden at both individual and society levels. Thus, it is currently recommended that youth engage on a daily basis in a minimum of 60-min of a moderate-to-vigorous PA (MVPA) (Strong et al. 2005; USDHHS 2008; WHO 2010). Public health endeavors at developing and implementing quality interventions at population level to thwart physical inactivity among youth - especially in the framework of childhood obesity and its co-morbities - are underway in several regions of the world (Hercberg 2006; Hill 2004; Neira \& de Onis 2005). For example, in France the launch by the French Ministry of Health of the French strategy for nutrition, physical activity and the prevention of obesity in 2002 (Hercberg 2006; Recours et al. 2011) appears as a milestone in the fight against physical inactivity and its related diseases. However, due to a number of political, cultural (Recours et al. 2011) and even, some philosophical reasons (Guinhouya et al. 2008), this ambitious program does not seem to work in young people as it was intended to (Recours et al. 2011).

An important body of epidemiological data have shown that childhood is the most physically active period of life (Ness et al. 2007; Riddoch et al. 2004; Trost et al. 2002; Verschuur \& Kemper 1985), but from adolescence PA engagement declines (Thompson et al. 2003; Trost et al. 2002; Verschuur \& Kemper 1985). Moreover, most studies have reported boys to be more active than girls whatever their chronological age (Armstrong \& Bray 1991; Falgairette et al. 1996; Ness et al. 2007; Riddoch et al. 2004; Trost et al. 2002). Furthermore, levels of annual decline range from $1.8 \%-2.7 \%$ for boys and $2.6 \%-7.4 \%$ for girls (Sallis 1993), suggesting that the decrease in PA may be more pronounced among girls than boys. Many reasons, including socio-cultural and psychosocial factors and their interactions, may underpin this phenomenon (Guinhouya et al. 2010; Trost et al. 1999). Nonetheless, some biological reasons seem to be involved in this sexual dimorphism, as on average girls mature earlier than boys (Mirwald et al. 2002). For instance, suppression of gender-related differences in children's self-reported PA have been found when PA data were adjusted for biological age (Thompson et al. 2003). This result was then confirmed by a number of studies using objective measures of young people's habitual PA (Drenowatz et 
al. 2010; Fairclough \& Ridgers 2010; Machado Rodrigues et al. 2010 ; Riddoch et al. 2007; Romon et al. 2004; Sherar et al. 2007; Wickel \& Eisenmann 2007; Wickel et al. 2009).

There is a variety of methods and indicators to determine the biological maturity of children and each has inherent limitations (Baxter-Jones et al. 2005; Beunen et al. 2006). Nonetheless, the timing of peak height velocity (PHV) is increasingly used in PA epidemiology as a measure of somatic maturity due to its close relationships with PA (Sherar et al. 2010). This method is particularly attractive for use in population studies because it is based on a non-invasive anthropometric approach (Mirwald et al. 2002). However, the classification system that may be used to build up groups of early, average and late maturing children remains unclear (Sherar et al. 2010), and this may complicate the comparability of studies. For example, some authors have used a gender-specific estimated age at PHV (APHV) to create and compare maturity categories (Wickel \& Eisenmann 2007) while these categories could have equally been based on the sample estimated APHV. Such a practice of unisex categorization is not yet widespread, perhaps due to the fact that the topic of PA and maturity level is a relatively new and growing research area. A particularly attractive alternative may be the use of data obtained from reference population samples such as those from the Saskatchewan Growth and Development study (Mirwald 1980), the Leuven Longitudinal Twin Study (Beunen et al. 2000 ) or the Zurich Longitudinal Growth Study (Largo et al. 1978) to control for the influence of gender on the distribution of the biological age of children.

Another concern in the existing literature is the consideration of wider chronological age ranges that combine preadolescents and adolescents, and therefore oblige authors to use chronological age as a covariate at the data analysis step. Although chronological age may independently influence the relationships between PA and biological age, only a few studies, using objective measures of PA, have involved a homogeneous group of prepubescents (Drenowatz et al. 2010; Fairclough \& Ridgers 2010). Furthermore, some of these data did not compare by gender on account of the inclusion of girls only (Drenowatz et al. 2010). Moreover, as recently suggested, little work has examined the influence of maturity status on levels of PA within each gender (Wickel et al. 2009), and the paucity of data about prepubescents is even more significant. Finally, only the absolute time spent in MVPA has been considered in previous analyses of maturity-related differences, and no study has examined the compliance of children to PA guidelines according to their maturity status. Such knowledge may help 
policy-decision makers and health promoters to adapt and develop interventions, which take this discrepancy into account.

Thus, the aims of the present study that exclusively involved prepubescent children were to examine, a) if maturity-related gender differences in MVPA is dependent on how maturity status is defined and measured; and b) the influence of the maturity level on compliance to PA recommendations.

\section{Methods}

\section{Participants}

A total of 253 children ( 139 boys) of cycle III (French equivalent of $3^{\text {rd }}, 4^{\text {th }}$, and $5^{\text {th }}$ grades) were recruited in six schools from the Education Authority Area of Lille. The study was conducted over two waves from September 2005 to March 2006 (wave 1) and from November 2007 to March 2008 (wave 2). Voluntary pupils and their parents/legal guardians were provided with full information about measurements and data collection procedures. To be included, children and their primary caregiver provided written informed consent, and the study received the approval of the local advisory board (Ethical Committee for the Protection of Persons of Lille).

\section{Anthropometry}

Stature and sitting stature were measured to the nearest $0.1 \mathrm{~cm}$ with a stadiometer (Seca 214, Hamburg, Germany). For stature, subjects were standing without shoes with their bodies stretched upward and their head in the Frankfort plane. Sitting stature was recorded in a similar posture with subjects sat on a ground sheet. Leg length was then calculated by subtracting sitting height from the complete stature. From stature and body mass, body mass index (BMI) was calculated as body mass $(\mathrm{kg}) / \mathrm{square}$ of stature $\left(\mathrm{m}^{2}\right)$. Chronological age was obtained by subtracting the children's date of birth from the date of observation.

\section{Maturity status}

Somatic maturity status was estimated by determining years from attainment of peak height velocity (PHV) using a non-invasive procedure (Mirwald et al. 2002). This procedure combines anthropometric data, age and their interactions, and is derived from regression equations that result in the estimation of years from PHV (sometimes referred to as "maturity offset" (Mirwald et al. 2002). Maturity offset was designed to be used either as a continuous variable to predict or to estimate the age at PHV (i.e., APHV = chronological age - maturity offset). The latter expression was considered as a sample-based criterion of biological 
maturity. A second maturity indicator (i.e., maturity status within gender) was further calculated as follows: participant's APHV minus mean APHV by gender (i.e., mean male or female APHVs from a reference sample). The mean APHVs by gender were from the Zurich Longitudinal Growth Study, which used values of 12.2 years and13.9 years for mean female APHV and mean male APHV, respectively (Largo et al. 1978). These gender-related average APHVs are similar to those reported from comparable populations (Malina et al. 2004; Tanner 1981). The centered APHV (i.e., a standardized criterion) was then used to build up maturity categories such that any negative value translated into "pre-APHV"; any positive value was considered as "post-APHV", whilst PHV was equal to zero.

\section{Physical activity assessment}

An objective assessment of PA over a whole week was performed using MTI Actigraph accelerometers (The ActiGraph, Model 7164, FL, USA). The devices were initialized to record PA in 30-sec epochs, but data were subsequently reintegrated in 1-min epochs to allow comparisons with previous studies. Accelerometers were tightly mounted at the right hip of each child at the beginning of the measurements. As the participants had no prior experience of wearing accelerometers they received a brief familiarization session where they were shown how to attach and remove the adjustable elastic Actigraph belt and the correct positioning of the instrument over the right hip. Children were encouraged to keep the device at night. Instructions were given regarding Actigraph removal (only during water-based activities, contact sports where risk of injury or monitor damage was high), and replacement (after any other occurrences of removal). Participants were encouraged to ignore the device whilst wearing it and go about their normal activities during the monitoring period.

Data reduction. Three to four days (2 school days and at least one free/weekend day) of measurement were selected for analysis. Data of the first and the final days of monitoring were deleted due to some reactivity risks on the first day of wearing and incomplete data on the final day. Furthermore, 3-4 days of Actigraph-based data have been shown to produce a reliability coefficient of 0.7-0.8.(Mattocks et al. 2008; Trost et al. 2000) Among children included in analysis, $68 \%$ provided four days of registration. Quality control of the data files was done using a visual inspection strategy. Data were submitted to a compliance check, during which sustained 20-min periods of zero counts were deleted because they were deemed to indicate non-wearing periods of the monitor (or lack of compliance with the protocol). Participants were 
removed from the database if they did not produce counts for $\geq 11.2 \mathrm{hrs}$ on each of the monitoring days. This figure represented non zero counts for at least $80 \%$ of a standard measurement day. Counts obtained between 07:00am and 09:00pm were summarized to portray PA outcomes.

The overall PA of children (i.e., total PA [TPA]) in accelerometer counts per minute (cpm) was calculated by averaging activity counts accumulated between 07:00am and 09:00pm. The time spent in MVPA per day (MVPA in min. $\mathrm{d}^{-1}$ ) was determined as the number of minutes spent above a moderate intensity PA cut-off point of $3200 \mathrm{cpm}$ (Puyau et al. 2002). Finally, adherence to PA recommendations was examined by estimating the proportion of children that spent $\geq 60 \mathrm{~min}^{-\mathrm{d}^{-1}}$ in a MVPA as required for youth (Strong et al. 2005; USDHHS 2008; WHO 2010).

\section{Statistical analysis}

The general characteristics of children were displayed as mean $\pm S D$ and range. Normal distributions of the data were examined using Kolmogorov-Smirnov test (completed with Lilliefors' correction). Gender differences in anthropometry were analyzed with independent Student " $f$ " tests or Mann and Whitney " $U$ " tests, as appropriate. A Chi-square test was used to determine associations between categorical variables. Between-day intraclass correlation coefficients (ICC and 95\% confidence intervals [Cls]) of absolute agreement using the two-way mixed Cronbach's model were computed to evaluate the reliability of PA data across the 3-4 days of assessment. Correlation analyses were carried out by Pearson Product moment coefficients of correlation to portray the nature of the relationships between centered APHV and PA within gender. An analysis of variance (ANOVA) was performed to examine gender differences in PA followed by an ANCOVA controlling for the estimated APHV. In all cases, the level of significance of analyses was set at $P<0.05$. Effect sizes were calculated using partial-eta squared $\left(\eta_{\mathrm{p}}{ }^{2}\right)$. Statistical analyses were performed using PASW ${ }^{\circledast}$ statistics v.18 (IBM SPSS Inc., Chicago, IL).

\section{Results}

\section{General characteristics}

As displayed in table 1, there were no significant differences between boys' and girls' chronological age $(P=0.77)$, stature $(P=0.95)$, body mass $(P=0.78)$ or $B M I(P=0.65)$. However, with an estimated APHV of $11.9 \pm 0.6$ years and a centered APHV of $-0.3 \pm 0.6$ years, girls were biologically older than boys $(13.4 \pm 0.7$ 
years and $-0.7 \pm 0.7$ years; $P<0.0001$ in each case). Overall, only $20 \%$ of the children were post-APHV, with this group consisting of a significantly higher proportion of girls than boys ( $58 \%$ vs. $42 \% ; P<0.05)$.

\section{Physical activity (PA), gender and biological maturity}

As for PA data, the single-day ICC for the total activity count (i.e., TPA) was $0.47(95 \% \mathrm{Cl}: 0.36 ; 0.57)$, and the average measurement ICC was 0.78 (95\% Cl: $0.69 ; 0.84)$. The corresponding ICCs for MVPA were $0.49(95 \% \mathrm{Cl}: 0.39 ; 0.60)$ and $0.80(95 \% \mathrm{Cl}: 0.72 ; 0.86)$.

As shown in Figures $1 A$ and $B$, gender-specific relationships between PA and centered APHV were generally weak. Nonetheless, there was a significant positive correlation between the TPA and centered APHV among girls $(r=0.21 ; P=0.028)$ but not in boys $(r=0.16 ; P=0.06)$. As for MVPA, a significantly positive correlation was found between the time spent by boys in MVPA ( $r=0.20 ; P=0.016)$, but not in girls $(r=0.13 ; P=0.155)$. Figures $1 A$ and $B$ show that children who were closer to PHV accumulated most TPA and MVPA, while both PA outcome measures were slightly lower among early and delayed maturing children). This pattern was clearer for MVPA than the TPA.

On the whole sample, boys were significantly more active than girls for both the total volume of PA (+23\%; $\left.F_{(1,252)}=23.06 ; P<0.0001 ; \eta_{p}^{2}=0.08\right)$ and the minutes they spent in MVPA $\left(+63 \% ; F_{(1,252)}=31.54\right.$; $P<0.0001 ; \eta_{p}^{2}=0.11$ ) (Tables 1; Figure 2). When the estimated APHV was controlled for (Figure 2A), the ANCOVA revealed no significant interactions between gender and APHV for both TPA $\left(F_{(1,249)}=0.23 ; P=\right.$ $\left.0.63 ; \eta_{p}^{2}=0.001\right)$ and MVPA $\left(F_{(1,249)}=0.008 ; P=0.93 ; \eta_{p}^{2}=0.000\right)$. Likewise, there were no significant main effects of gender on both TPA $\left(F_{(1,249)}=0.35 ; P=0.55 ; \eta_{p}^{2}=0.001\right)$ and MVPA $\left(F_{(1,249)}=0.06 ; P=\right.$ $\left.0.81 ; \eta_{p}^{2}=0.000\right)$. On the other hand, there were significant main effects of the estimated APHV on both $\operatorname{TPA}\left(F_{(1,249)}=6.55 ; P=0.011 ; \eta_{p}^{2}=0.026\right)$ and MVPA $\left(F_{(1,249)}=6.12 ; P=0.014 ; \eta_{p}^{2}=0.024\right)$.

\section{Achievement of PA guidelines by gender and maturity}

On the whole sample, only $9.1 \%$ of children met the recommendation of $60 \mathrm{~min} /$ day in a MVPA. In general, more boys $(14.4 \%)$ met PA recommendations than girls $(2.6 \%)(P=0.002)$. This observation also applied regardless of maturity categories, (pre-APHV: $12.7 \%$ of boys vs. $2.4 \%$ of girls, $\mathrm{P}<0.001$; postAPHV: $23.8 \%$ of boys vs. $3.4 \%$ of girls, $\mathrm{P}<0.0001$ ) (Figure 3). As shown in Figure 3, more post-APHV children (12.0\%) achieved the PA recommendations than pre-APHV children (8.4\%), but the difference did not reach significance $(P=0.60)$. Within each gender, there were no significant differences between pre- 
APHV and post-APHV children, even if a relatively important gradation in the compliance with the PA recommendations can be observed from pre-APHV (12.7\%) to post-APHV (23.8\%) among boys ( $\mathrm{P}=0.08)$.

\section{Discussion}

The study findings suggest that analysis of the influence of biological maturity on gender-related differences in PA may produce contrasting results according to the strategy used to depict maturity status. Indeed, the effect of gender on the total volume of PA and MVPA was maintained after controlling for the standardized maturity criterion, whereas this effect was lost if children were aligned on the raw estimated age at peak height velocity (APHV). In this sample, boys were found to engage in a higher volume of PA and to spend more time in MVPA as well as be more likely to achieve PA guidelines than girls. This observation was consistent when boys and girls were compared at a given maturity level.

In a recent review (Sherar et al. 2010), inconsistencies in studies dealing with the effect of biological maturity on the activity level of adolescents were pinpointed. For instance, while some studies reported no difference in PA according to the maturity status of children (Niven et al. 2007 ; Wickel et al. 2009), others found a decrease in PA with increasing biological age (Sherar et al. 2007; Thompson et al. 2003). In the current study, the PA level of these preadolescent children tended to increase slightly from the pre-APHV status up to the edge of their expected PHV. Although direct comparisons between these studies are difficult given the discrepancy in the choice of maturity indicators (e.g., pubertal development scale vs. predicted age at PHV) (Sherar et al. 2010) and in the methods used for PA (subjective vs objective measurements), the controversial findings are particularly important among girls, even between studies that used similar PA assessment protocols. For instance, using accelerometry, Baker and coworkers (Baker et al. 2007) revealed that advanced maturing girls accumulated fewer minutes in MVPA than delayed maturing girls. This contrasts with existing data on the absence of differences in MVPA between maturity groups, reported elsewhere (Sherar et al. 2009; Wickel et al. 2009). In the current study, whatever the strategy used to determine maturity status, there was a relatively modest, yet steady increase in total volume of PA (and to a lesser extent in MVPA) among girls categorized as preadolescent. Conversely, boys showed a steady increase in MVPA up to the PHV, which differs from previous data (Wickel et al. 2009). These findings can be explained in part by differences in the chronological age of the children in Wickel et al.'s study (12 year-old on average) compared to those involved in the present study who 
averaged 10 years old. An additional and more important explanation may lie on the data reduction strategy used to depict the MVPA of children. Previous studies have employed an age-specific count-toMET conversion equation to define moderate-intensity PA (Freedson et al. 2005). This cut-point would translate on average to $1200 \mathrm{cpm}$ if applied to the children in our study. This cut-point is almost three times lower than the $3200 \mathrm{cpm}$ cut-off point used in the present study. The effect of such a gap in the estimation of MVPA has previously been discussed (Guinhouya et al. 2006). Furthermore, the implications of using other MVPA cut-points when investigating the influence of biological maturity on boys' and girls' MVPA has recently been highlighted (Zitouni \& Guinhouya 2011).

Despite the mixed findings regarding the association between PA and the biological maturity of youth, a growing body of consistent data has shown that maturity clearly offsets the gender-differences in PA among both preadolescents (Drenowatz et al. 2010; Eaton \& Yu 1989 ; Fairclough \& Ridgers 2010; Wickel et al. 2009) and adolescents (Cumming et al. 2008 ; Cumming et al. 2011; Davison et al. 2007 ; Machado Rodrigues et al. 2010 ; Sherar et al. 2007; Thompson et al. 2003; Wickel \& Eisenmann 2007). It is noteworthy that this observation remains outstandingly consistent whatever the indicator used for maturity (e.g., percent of predicted adult height vs. pubertal development scale vs. predicted APHV) (Cumming et al. 2008 ; Cumming et al. 2011; Davison et al. 2007 ; Thompson et al. 2003) and as PA is self-reported (Cumming et al. 2008 ; Cumming et al. 2011; Eaton \& Yu 1989 ; Thompson et al. 2003) or objectively measured (Davison et al. 2007 ; Drenowatz et al. 2010; Fairclough \& Ridgers 2010; Sherar et al. 2007; Wickel \& Eisenmann 2007; Wickel \& Eisenmann 2007). In the current study, such an attenuation effect of maturity may be seen only with the sample-based maturity status (i.e., the raw APHV) but not with maturity status relative to sex (i.e., centered APHV). This is due to the fact that the estimated APHV is by definition a gender-dependent variable (Figure $2 A$ ) that may mechanically nullify the gender-related difference in PA among children. Conversely, the centered APHV, which considers maturation status within sex, allows direct comparisons between boys and girls across a large range of biological ages (Figure 2B). When compared to other accelerometer studies, these unexpected findings can be explained once again by the discrepancy in the data reduction strategy. The use of different ActiGraph-based cut-points remains a great matter of concern in the field of PA epidemiology (Guinhouya et al. 2009; Guinhouya et al. 2009) and should be considered when interpreting the inconsistency between studies. In the present analysis there 
1

2

3

4

5

7

8

9

10

was no need to control for chronological age since the sample was quite homogeneous (i.e., only prepubescent) in this regard. The average maturity offset of included children was about $-2.6 \mathrm{PHV}$. Thus, the finding of no attenuation effect of the maturity status on the gender-related difference in MVPA seems to be in line with a previous study that supported the persistence of a difference between boys and girls at -3 PHV (Thompson et al. 2003). Paradoxically, another study from the same research group found no difference between boys and girls at a maturity offset of -3 PHV (Sherar et al. 2007), possibly because of the cut-off point used to define the moderate-intensity of PA (Guinhouya \& Hubert 2008).

It is now well-documented that boys not only spent more time in MVPA than girls (Armstrong \& Bray 1991; Falgairette et al. 1996; Ness et al. 2007; Riddoch et al. 2004; Trost et al. 2002), but some studies have also revealed that a higher proportion of boys met the PA recommendations when compared to their female peers (Guinhouya et al. 2010; Riddoch et al. 2007; Troiano et al. 2008). Likewise, the adherence to these guidelines seems to decrease with chronological age (Troiano et al. 2008). No previous studies have related compliance with these guidelines to the maturity status of youth; hence an aim of the present study was to shed some light on this issue. Our data suggest that advanced maturing prepubescents are most likely to achieve the recommendations. However, due to the relatively small sample size, further studies are needed to strengthen this conclusion.

From a practical standpoint the current study suggests two main implications for public health decisions and health promotion strategies. First, there may be a need to stimulate the growth and development of late maturing children, as their activity levels were relatively low. At a population level, this could be carried out by augmenting the daily PA levels of children and youth, as PA is a potentially important contributor to growth (Bailey et al. 1999). Moreover, girls should be targeted as early as possible (i.e., before puberty) through thorough consideration of the main barriers to and facilitators of girls' PA (Cumming et al. 2011; Davison \& Deane 2010; Fairclough \& Ridgers 2010; Jago et al. 2011). It should though be acknowledged that most of the children $(>90 \%)$ in the current study did not meet the PA recommendations. Thus, as indicated by recent research (Apété et al. 2012; Guinhouya et al. 2010), this low proportion of physically active children justifies the need for an aggressive PA promotion program in this area of Northern France. However, the use of a less stringent MVPA cut-point, such as the $2296 \mathrm{cpm}$ (Evenson et al. 2008 ; Trost et al. 2011), may result in a substantial increase of the proportion of children achieving PA 
recommendations, which might alter resultant PA promotion strategies. Thus, further studies using multiple cut-points may help to get a clearer indication of the relationship between gender, maturation and PA, which would allow policy makers and researchers to design and apply interventions using appropriate approaches..

There are some limitations to the current study, including the relatively small sample size, which may weaken the examination of the associations between the prevalence of PA and maturity categories. As stated earlier, future studies are needed to address this issue. A second limitation is related to the way the sitting height of children has been assessed in the current study, which did not fully complied with standard procedures (Lohman et al. 1988). However, measurements were performed by trained specialists, using a rigorous approach to gather at least two measurements for each anthropometric parameter, including the sitting height. Moreover, our results on the estimated APHV that requires the sitting height, are similar to those provided by previous studies, which involved children of the same chronological age range (Fairclough \& Ridgers 2010; Janz et al. 2008).

Besides these limitations, the current study indicates that among prepubescent children the influence of biological maturity on gender-differences in PA may be a function of how maturity status is determined. The most physically active group in this sample seemed to be children whose growth matched with the expected values (i.e., on-time children). Furthermore, precocity, and especially closeness to age at PHV, seemed to stimulate adherence of these children to PA recommendations. Because the BMI and body composition of children are related to both PA and the biological maturity, future studies in the age group that also control for fat mass or fat free mass may enhance the discussion on this topic. 


\section{Conflicts of interest: None}

1

2

3

4

5

6

7

8

9

10

11

12

13

14

15

16

17

18

19

20

21

22

23

24

25

26

27

28

29

30

31

34

35

36

37

38

39

40

41

42

43

44

45

46

47

48

49

50

51

52

53

54

55

56

57

58

59

60

Child: Care, Health and Development 


\section{References}

Apété, G. K., Zitouni, D., Hubert, H. \& Guinhouya, B. C. (2012). Compliance of children in northern France with physical activity recommendations. Perspect Public Health. 132: 81-88.

Armstrong, N. \& Bray, S. (1991). Physical activity patterns defined by continuous heart rate monitoring. Arch Dis Child. 66: 245-247.

Bailey, D. A., McKay, H. A., Mirwald, R. L., Crocker, P. R. \& Faulkner, R. A. (1999). A six-year longitudinal study of the relationship of physical activity to bone mineral accrual in growing children: the university of Saskatchewan bone mineral accrual study. J Bone Miner Res. 14: 1672-1679.

Baker, B. L., Birch, L. L., Trost, S. G. \& Davison, K. K. (2007). Advanced pubertal status at age 11 and lower physical activity in adolescent girls. J Pediatr. 151: 488-493.

Baxter-Jones, A. D. G., Eisenmann, J. C. \& Sherar, L. B. (2005). Controlling for maturation in pediatric exercise science. Ped Exerc Sci. 17: 18-30.

Beunen, G., Thomis, M., Maes, H. H., Loos, R., Malina, R. M., Claessens, A. L. \& Vlietinck, R. (2000 ). Genetic variance of adolescent growth in stature. Ann Hum Biol. 27: 173-186.

Beunen, G. P., Rogol, A. D. \& Malina, R. M. (2006). Indicators of biological maturation and secular changes in biological maturation. Food Nutr Bull. 27: S244-S256.

Chen, X. \& Wang, Y. (2008). Tracking of blood pressure from childhood to adulthood. Circulation. 117: 31713180.

Cumming, S. P., Standage, M., Gillison, F. \& Malina, R. M. (2008 ). Sex differences in exercise behavior during adolescence: is biological maturation a confounding factor? J Adolesc Health. 42: 480-485.

Cumming, S. P., Standage, M., Loney, T., Gammon, C., Neville, H., Sherar, L. B. \& Malina, R. M. (2011). The mediating role of physical self-concept on relations between biological maturity status and physical activity in adolescent females. J Adolesc. [Epub ahead of print].

Davison, K. K. \& Deane, G. D. (2010). The consequence of encouraging girls to be active for weight loss. Soc Sci Med. 70: 518-525.

Davison, K. K., Werder, J. L., Trost, S. G., Baker, B. L. \& Birch, L. L. (2007). Why are early maturing girls less active? Links between pubertal development, psychological well-being, and physical activity among girls at ages 11 and 13. Soc Sci Med. 64: 2391-2404.

Drenowatz, C., Eisenmann, J. C., Pfeiffer, K. A., Wickel, E. E., Gentile, D. \& Walsh, D. (2010). Maturity-related differences in physical activity among 10- to 12-year-old girls. Am J Hum Biol. 22: 18-22.

Eaton, W. O. \& Yu, A. P. (1989). Are sex differences in child motor activity level a function of sex differences in maturational status? Child Dev. 60: 1005-1011.

Evenson, K. R., Catellier, D. J., Gill, K., Ondrak, K. S. \& McMurray, R. G. (2008 ). Calibration of two objective measures of physical activity for children. J Sports Sci. 26: 1557-1565.

Fairclough, S. J. \& Ridgers, N. D. (2010). Relationships between maturity status, physical activity, and physical self-perceptions in primary school children. J Sports Sci. 28: 1-9.

Falgairette, G., Gavarry, O., Bernard, T. \& Hebbelinck, M. (1996). Evaluation of habitual physical activity from a week's heart rate monitoring in French school children. Eur J Appl Physiol. 74: 153-161. 
Freedson, P., Pober, D. \& Janz, K. F. (2005). Calibration of accelerometer output for children. Med Sci Sports Exerc. 37: S523-S530.

Guinhouya, B. C., Apété, G. K. \& Hubert, H. (2009). Diagnostic quality of Actigraph-based physical activity cutoffs for children: What overweight/obesity references can tell? Pediatr Int. 51: 568-573.

Guinhouya, B. C., Apété, G. K. \& Hubert, H. (2010). The determinants of habitual physical activity (HPA) in children: update and implications for care and prevention options in pediatric overweight/obesity. [Actualité sur les déterminants de l'activité physique habituelle (APH) de l'enfant : Mise à jour et implications pour les options de prise en charge et de prévention du surpoids/obésité infantile]. Rev Epidemiol Sante Publique. 58: 49-58.

Guinhouya, B. C., Dupont, G. \& Hubert, H. (2008). Physical activity epidemiology applied to French children and adolescents: Barriers and opportunities. [Epidémiologie de l'activité physique appliquée aux enfants et adolescents français: Barrières et possibilités]. Prat Organ Soins. 39: 125-132.

Guinhouya, B. C., Hubert, H. \& Zitouni, D. (2011). Need for an unbiased computation of the moderate-intensity physical activity of youth in epidemiologic studies. Am J Prev Med. 41: e1-2.

Guinhouya, B. C., Vilhelm, C., Allogio, C., Apété, G. K., Zitouni, D., Redlich, Y. \& Hubert, H. (2010). Level of objectively-measured physical activity among children of Northern France. Bull Epidemiol Heb. 27-28: 297-301.

Guinhouya, C. B. \& Hubert, H. (2008). Incoherence with studies using actigraph mti among children aged 6-12 yr. Med Sci Sports Exerc. 40: 979-980.

Guinhouya, C. B., Hubert, H., Soubrier, S., Vilhelm, C., Lemdani, M. \& Durocher, A. (2006). Moderate-to-vigorous physical activity among children: discrepancies in accelerometry-based cut-off points. Obesity. 14: 774-777.

Guinhouya, C. B., Lemdani, M., Vilhelm, C., Durocher, A. \& Hubert, H. (2009). Actigraph-defined moderate-tovigorous physical activity cut-off points among children: statistical and biobehavioural relevance Acta Paediatr. 98: 708-714.

Hercberg, S. (2006). Eléments du bilan du PNNS (2001-2005) et propositions de nouvelles stratégies pour le PNNS2 (2006-2008). INSERM, Paris: 280.

Hill, J. (2004). Physical activity and obesity. Lancet. 363: 182.

Jago, R., Davison, K. K., Brockman, R., Page, A. S., Thompson, J. L. \& Fox, K. R. (2011). Parenting styles, parenting practices, and physical activity in 10- to 11-year olds. Prev Med. 52: 44-47.

Janz, K. F., Medema-Johnson, H. C., Letuchy, E. M., Burns, T. L., Gilmore, J. M., Torner, J. C., Willing, M. \& Levy, S. M. (2008). Subjective and objective measures of physical activity in relationship to bone mineral content during late childhood: the lowa Bone Development Study. Br J Sports Med. 42: 658-663.

Largo, R. H., Gasser, T., Prader, A., Stuetzle, W. \& Huber, P. J. (1978). Analysis of the adolescent growth spurt using smoothing spline functions. Ann Hum Biol. 5: 421-434.

Lohman, T. G., Roche, A. F. \& Martorell, R. Anthropometric standardization reference manual. Champaign: IL: Human Kinetics 1988.

Machado Rodrigues, A. M., Coelho e Silva, M. J., Mota, J., Cumming, S. P., Sherar, L. B., Neville, H. \& Malina, R. M. (2010). Confounding effect of biologic maturation on sex differences in physical activity and sedentary behavior in adolescents. Pediatr Exerc Sci. 22: 442-453.

Malina, R., Bouchard, C. \& Bar Or, O. Growth, Maturation, and Physical Activity. 2nd ed. Champaign, IL: Human Kinetics 2004. 
Mattocks, C., Ness, A., Leary, S., Tilling, K. \& Blair, S. N., et al. (2008). Use of accelerometers in a large fieldbased study of children: protocols, design issues, and effects on precision. J Phys Act Health. 5 (Suppl 1): S98S111.

Mirwald, R. L. Saskatchewan growth and development study. In: Ostyn M., Beunen G. \& Simons J., eds. Kinanthropometry II. Baltimore, MD: University Park Press, 1980:289-305.

Mirwald, R. L., Baxter-Jones, A. D. G., Bailey, D. A. \& Beunen, G. (2002). An assessment of maturity from anthropometric measurements. Med Sci Sport Exerc. 34: 689-694.

Morrison, J. A., Friedman, L. A., Wang, P. \& Glueck, C. J. (2008). Metabolic syndrome in childhood predicts adult metabolic syndrome and type 2 diabetes mellitus 25 to 30 years later. J Pediatr. 152: 201-206.

Neira, M. \& de Onis, M. (2005). Prventing obesity: a public health priority in Spain. Lancet. 365: 1386.

Ness, A. R., Leary, S. D., Mattocks, C., Blair, S. N., Reilly, J. J., Wells, J., Ingle, S., Tilling, K., Smith, G. D. \& Riddoch, C. (2007). Objectively measured physical activity and fat mass in a large cohort of children. PLoS Med. 4: e97.

Niven, A. G., Fawkner, S. G., Knowles, A. M. \& Stephenson, C. (2007 ). Maturational differences in physical selfperceptions and the relationship with physical activity in early adolescent girls. Pediatr Exerc Sci. 19: 472-480.

Puyau, M. R., Adolph, A. L., Vohra, F. A. \& Butte, N. F. (2002). Validation and calibration of physical activity monitors in children. Obesity Res. 10: 150-157.

Recours, R., Hanula, G., Travert, M., Sabiston, C. \& Griffet, J. (2011). Governmental interventions and youth physical activity in France. Child Care Health Dev. 37: 309-312.

Riddoch, C., Andersen, L.-B., Wedderkopp, N., Harro, M., Klasson-Heggebo, L., Sardinha, L. B., Cooper, A. R. \& Ekelund, U. (2004). Physical activity levels and patterns of 9- and 15-yr-old European children. Med Sci Sports Exerc. 36: 86-92.

Riddoch, C. J., Mattocks, C., Deere, K., Saunders, J., Kirkby, J., Tilling, K., Leary, S. D., Blair, S. N. \& Ness, A. (2007). Objective measurement of levels and patterns of phyiscal activity. Arch Dis Child. 92: 963-969.

Romon, M., Lafay, L., Bresson, J. L., Oppert, J. M., Borys, J. M., Kettaneh, A. \& Charles, M. A. (2004). Relationships between physical activity and plasma leptin levels in healthy children: the Fleurbaix-Laventie Ville Santé II Study. Int J Obes Relat Metab Disord. 28: 1227-1232.

Sallis, J. F. (1993). Epidemiology of physical activity and fitness in children and adolescents. Crit Rev Food Sci Nutr. 33: 403-408.

Sherar, L. B., Cumming, S. P., Eisenmann, J. C., Baxter-Jones, A. D. \& Malina, R. M. (2010). Adolescent biological maturity and physical activity: biology meets behavior. Pediatr Exerc Sci. 22: 332-349.

Sherar, L. B., Esliger, D. W., Baxter-Jones, A. D. G. \& Tremblay, M. S. (2007). Age and Gender Differences in Youth Physical Activity: Does Maturity Matter? Med Sci Sports Exerc. 39: 830-835.

Sherar, L. B., Gyurcsik, N. C., Humbert, M. L., Dyck, R. F., Fowler-Kerry, S. \& Baxter-Jones, A. D. (2009). Activity and barriers in girls (8-16 yr) based on grade and maturity status. Med Sci Sports Exerc. 41: 87-95.

Strong, W. B., Malina, R., Blimkie, C. J., Daniels, S. R., Dishman, R. K., Gutin, B., Hergenroeder, A. C., Must, A., Nixon, P. A., Pirvarnik, J. M., Rowland, T., Trost, S. G. \& Trudeau, F. (2005). Evidence based physical activity for school-age youth. J Pediatr. 146: 732-737.

Tanner, J. M. History of the study of human growth. Cambridge, UK: Cambridge University Press 1981. 
Thompson, A. M., Baxter-Jones, A. D. G., Mirwald, R. L. \& Bailey, D. A. (2003). Comparison of physical activity in male and female children: Does maturity matter? Med Sci Sport Exerc. 35: 1684-1690.

Troiano, R. P., Berrigan, D., Dodd, K. W., Masse, L. C., Tilert, T. \& McDowell, M. (2008). Physical activity in the US measured by accelerometer. Med Sci Sports Exerc. 40: 181-188.

Trost, S. G., Loprinzi, P. D., Moore, R. \& Pfeiffer, K. A. (2011). Comparison of accelerometer cut points for predicting activity intensity in youth. Med Sci Sports Exerc. 43: 1360-1368.

Trost, S. G., Pate, R. R., Freedson, P. S., Sallis, J. F. \& Taylor, W. C. (2000). Using objective physical activity measures with youth: How many days of monitoring are needed? Med Sci Sports Exerc. 32: 426-431.

Trost, S. G., Pate, R. R., Sallis, J. F., Freedson, P. S., Taylor, W. C., Dowda, M. \& Sirard, J. (2002). Age and gender differences in objectively measured physical activity in youth. Med Sci Sports Exerc. 34: 350-355.

Trost, S. G., Pate, R. R., Ward, D. S., Saunders, R. \& Riner, W. (1999). Correlates of objectively measured physical activity in preadolescent youth. Am J Prev Med. 17: 120-126.

USDHHS (2008). Physical Activity Guidelines Advisory Committee. Physical Activity Guidelines Advisory Committee Report, 2008. U.S. Department of Health and Human Services, Washington, DC.

Verschuur, R. \& Kemper, H. C. G. (1985). The pattern of daily physical activity. Med Sci Sport Exerc. 20: 169186.

WHO (2010). Global recommendations on physical activity for health. World Health Organization (WHO), Geneva: 60 .

Wickel, E. E. \& Eisenmann, J. C. (2007). Contribution of Youth Sport to Total Daily Physical Activity among 6- to 12-yr-old Boys Med Sci Sports Exerc. 39: 1493-1500.

Wickel, E. E. \& Eisenmann, J. C. (2007). Maturity-related differences in physical activity among 13- to 14-year-old adolescents. Pediatr Exerc Sci. 19: 384-392.

Wickel, E. E., Eisenmann, J. C. \& Welk, G. J. (2009). Maturity-related variation in moderate-to-vigorous physical activity among 9-14 year olds. J Phys Act Health. 6: 597-605.

Zitouni, D. \& Guinhouya, B. C. (2011). Maturity negates the gender-related difference in physical activity among youth. Is this equally justified whatever the accelerometer cut-off point used? J Sci Med Sport (in press). doi:10.1016/j.jsams.2011.11.254. 
Table 1 Anthropometric characteristics, somatic maturity and physical activity parameters (mean \pm SD, and range)

\begin{tabular}{|c|c|c|c|c|c|c|c|c|}
\hline & $\begin{array}{l}\text { Age } \\
\text { (yrs) }\end{array}$ & $\begin{array}{c}\text { APHV } \\
\text { (yrs) } \\
\end{array}$ & $\begin{array}{c}\text { Centered* } \\
\text { APHV }\end{array}$ & $\begin{array}{l}\text { Stature } \\
(m)\end{array}$ & $\begin{array}{c}\text { Body mass } \\
(\mathrm{kg})\end{array}$ & $\begin{array}{c}\mathrm{BMl} \\
\left(\mathrm{kg} / \mathrm{m}^{2}\right)\end{array}$ & $\begin{array}{c}\text { Total activity } \\
(\mathrm{cpm})\end{array}$ & $\begin{array}{l}\text { MVPA } \\
\left(m i n \cdot d^{-1}\right) \\
\end{array}$ \\
\hline $\begin{array}{c}\text { Boys } \\
(n=139)\end{array}$ & $\begin{array}{c}9.9 \pm 0.9 \\
{[7.6,12.4]}\end{array}$ & $\begin{array}{c}13.4 \pm 0.7 \\
{[11.4,14.9]}\end{array}$ & $\begin{array}{c}-0.7 \pm 0.7 \\
{[-2.5,0.9]}\end{array}$ & $\begin{array}{c}1.40 \pm 0.07 \\
{[1.23,1.61]}\end{array}$ & $\begin{array}{c}35.6 \pm 9.0 \\
{[22.5,71.6]}\end{array}$ & $\begin{array}{c}18.0 \pm 3.2 \\
{[13.5,29.4]}\end{array}$ & $\begin{array}{c}621 \pm 211 \\
{[194,1464]}\end{array}$ & $\begin{array}{c}39 \pm 23 \\
{[4,151]}\end{array}$ \\
\hline $\begin{array}{c}\text { Girls } \\
(n=114)\end{array}$ & $\begin{array}{c}9.9 \pm 0.8 \\
{[7.9,11.7]}\end{array}$ & $\begin{array}{c}11.9 \pm 0.6^{\dagger} \\
{[10.2,13.9]}\end{array}$ & $\begin{array}{c}-0.3 \pm 0.6^{\dagger} \\
{[-1.9,-1.7]}\end{array}$ & $\begin{array}{c}1.40 \pm 0.08 \\
{[1.22 ; 1.63]}\end{array}$ & $\begin{array}{c}35.9 \pm 8.5 \\
{[21.5,59.9]}\end{array}$ & $\begin{array}{c}18.2 \pm 3.1 \\
{[12.6,26.6]}\end{array}$ & $\begin{array}{c}503 \pm 142^{\dagger} \\
{[237,1223]}\end{array}$ & $\begin{array}{l}24 \pm 14^{\dagger} \\
{[6,103]}\end{array}$ \\
\hline
\end{tabular}

BMI: body mass index; APHV: age at the peak height velocity; MVPA: moderate-to-vigorous physical activity † denotes a significant difference between boys and girls, $P<0.0001$

* this value results from the difference between each participant estimated APHV and the mean APHVs by gender (i.e. APHVs of $12.2 \mathrm{yrs}$ and 13.9 yrs for girls and boys, respectively according to the Zurich Longitudinal Growth Study) 


\section{Figure caption}

Figure 1: Relationships between physical activity and biological maturity by gender

- Figure 1A: Total volume of physical activity by gender and the centered age from the peak height velocity (APHV)

- Figure 1B: Moderate-to-vigorous physical activity (MVPA) by gender and the centered age from the peak height velocity (APHV)

Figure 2: Illustration of physical activity patterns according to different biological maturity indices

- Figure 2A: Pattern of MVPA by gender according to the centered APHV

- Figure 2B: Pattern of MVPA by gender according to the estimated APHV

\section{Figure 3: Proportion of children meeting the 60 min.d-1 of MVPA by gender and maturity categories}

- Grey box for female

- Black box for male 


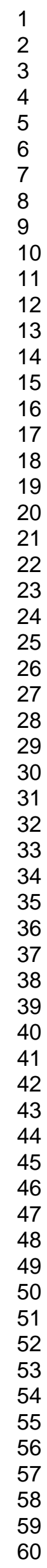

Figure 1

$296 \times 209 m m(96 \times 96$ DPI)

Child: Care, Health and Development 

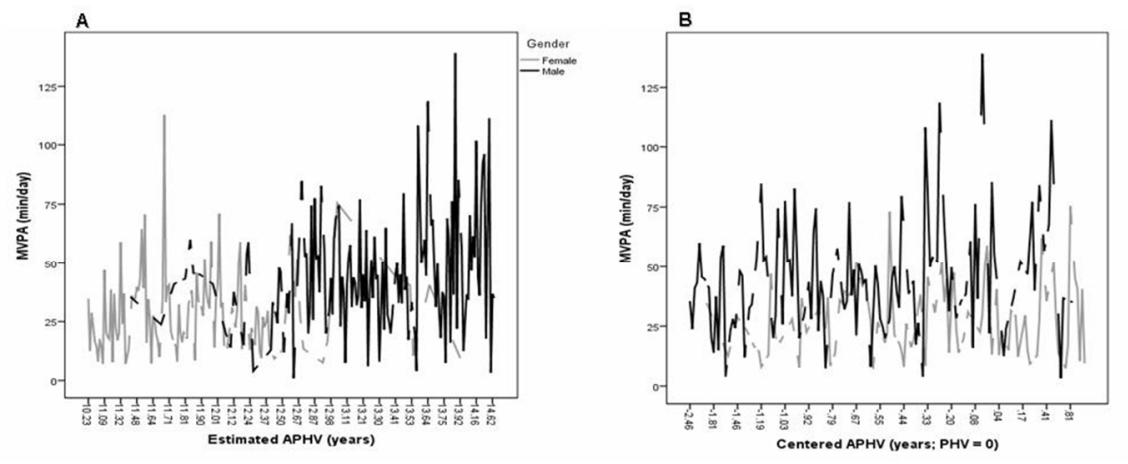

Figure 2

$296 \times 209 m m(96 \times 96$ DPI) 


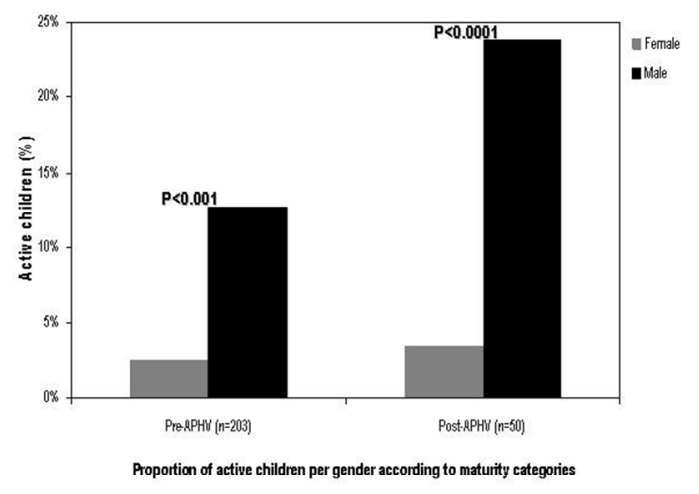

Figure 3

$296 \times 209 m m(96 \times 96$ DPI)

34

35

36

37

38

39

40

41

42

43

44

45

46

47

48

49

50

51

52

53

54

55

56

57

58

59

60

Child: Care, Health and Development 